the remarkable insight of his work, which contained the seeds of most of the more recent developments. To say this is not to decry the achievements of later researchers who have used techniques of mathematical analysis or numerical solution which were not formerly available. Further progress must depend largely on a better understanding of the processes acting at the air-sea interface and of turbulence within the ocean. The last section deals with the special features of particular current systems. The discussion of the equatorial system includes a good account of our present knowledge of the equatorial undercurrents in all three oceans. A similar treatment is given of western and eastern boundary currents and of the Antarctic cireumpolar current. The book ends with a comprehensive list of references and a good index. It is to be thoroughly recommended as a textbook for the student of physical oceanography, as an introduction to more advanced dynamical treatments or as a reference book for other marine scientists.

K. F. BOWDEN

\section{MASERS AND LASERS}

\section{Solid-State Masers}

By E. B. Tucker. (Solid-State Physics.) Pp. xii +96 (Routledge and Kegan Paul: London; Dover: New York, January 1969.) $8 s$.

MASERs and lasers have become such well known objects that the physical basis for their operation will be of interest to a far wider range of people than the specialist alone. Most physicists, either at undergraduate or research level, and many engineers and chemists, will be glad of the opportunity to read a brief survey of the subject, and this book satisfies just this requirement.

Whilst being careful not to weigh the reader down with unnecessary mathematics, the author has presented the physics of the maser in a way that brings out the logic of the system and the physical principles on which it is based. Such concepts as Planck's distribution law for the mean energy of an oscillator and the transition rates between states in a three level system are treated in just sufficient detail to allow someone with a modicum of university physics to understand the reasons for their being included.

About half the book is concerned with the background physics required for understanding maser action, including the properties of radiation, amplifiers and noise. The starting points are Maxwell's equations and a few elements of quantum theory. A clear description of the methods of inversion used in lasers is followed by a discussion of a few practical examples of solid state masers, and the book is rounded off with some general properties of masers.

Although the book fails to reach one hundred pages, and may contain rather too much introductory physics for the more advanced physicist, there cannot be many scientists who would regret spending eight shillings for this monograph. The style of the writing will appeal to those who prefer a direct approach rather than a colourful one, although there are one or two places where the directness does appear a little jerky. A. Mirlington

\section{GROUNDING IN NUCLEAR PHYSICS}

\section{Nuclear Physics}

An Introduction. By Haro Von Buttlar. Translated from the German by Fernando B. Morinigo. Pp. xii +547. (Academic Press: New York and London, November 1968.) $135 s 4 d$.

THE intention of the author is to "present the fundamentals of nuclear physics by means which are not beyond the grasp of undergraduate students . . .". In this particular case, this statement must be taken to imply a more limited scope than might be found in less thorough texts. The author aims to give a fairly complete, detailed, theoretical treatment of each topic at a moderately elementary level. Quite clearly, it is not possible to do justice in this way to some topics, but it remains arguable just how far this concern for detail should be allowed to dictate the choice of subject matter. For example, an excellent account of $\beta$-decay is given, but the non-conservation of parity in weak interactions is relegated to a brief, albeit lucid, discussion. It would seem preferable, in an introductory text, to give, in addition to the detailed treatments, extended qualitative discussions of the more important but difficult topics so that the student reader does not lose the correct balance in the overall broader picture of the subject. A related point, but of minor concern, is that no experimental details are included. Perhaps some indication of the theoretical bias could have been given in the title.

The arrangement of the book is straightforward and logical. The first part does not assume any knowledge of quantum mechanics, and starts with a review of the classical mechanics of collision and central force problems. It then goes on to deal with various topics, for example, mass defects, Q-equations, which can be given an adequate discussion at an elementary level without resort to quantum mechanies. The second part deals with the basic wave mechanics, and the final section applies to nuclear reactions and the properties of nuclei.

The success of the book must surely rest with the excellent manner in which the student is taken step by step through the derivations of many important formulae and the careful way in which the implications of the various theoretical models are discussed. It is done with as few breaks in the logic as possible, and where difficult steps, which cannot be covered in full, arise, adequate references to the relevant literature are given. The result is a self-contained textbook which covers meticulously and clearly much of the groundwork of nuclear physics.

John M. TitmaN

\section{Correspondence}

\section{Mr Benn's Parish}

SIR,-We must challenge a sweeping statement in Nature concerning the Concorde project. The leading editorial "Mr. Benn's Parish" (221, 297; 1969) states: "Even if, as everybody hopes, the outcome is a successful commercial aircraft, there is very little hope that the full cost of development will be recovered in sales". With the latter half of the sentence we are happy to agree; but it is our own hope that the Concorde will not be "a successful commercial aircraft".

We are not Anglophobes or Francophobes; we, and similar European groups ${ }^{1}$, oppose impartially all commercial supersonic transport projects, including especially the projected American Boeing SST. We oppose them because, if successful, they will contaminate the human environment with a new form of noise pollution which will be exceedingly unpleasant to most people and virtually intolerable to many. Recently an expert in the field, Dr Karl D. Kryter, has analysed the extensive available data on human response to sonic booms from supersonic transport (Science, 163, 359; 1969). He asks (p. 362), "Will the population of the United States 'pay' the price of the annoyance and discomfort of being exposed to the booms from the regular operation of planned SSTs?" and he 
concludes from extensive evidence that the answer appears to be a definite "no"; indeed that "no data can be found to suggest that any other conclusion is possible". You are aware of the passionate protests, which led sometimes to legal action, by people living in the immediato vicinity of London Airport, who suffered from the noise of jet planes. Imagine such protests, spread throughout most of the entire population of Great Britain, and you can picture the consequences of a regular programme of supersonic flights over populated areas. For the detailed evidence one must refer to Kryter's article, and to tho reports he cites. Ho emphasizes that his conclusions are based on objective data concerning human response to sonic booms, and do not lean in any way on "humanitarian conjectures" regarding the effects of sonic booms on human health and wellbeing.

A full fledged programme of commercial supersonic flights across the United States, as formerly envisaged, would also lead to extensive property damage, estimated by Kryter from the available data, on damage claims duo to sonic booms from military planes, as amounting to 40 to 80 million dollars per year. Our own estimates ${ }^{2}$ from the same data would run several times as high as this. In any case the anticipated damage would be substantial, for both the Concorde and the American SST will produce booms with substantially higher overpressures than the military planes used in the tests.

Concerning the Concorde, your cditorial states "it would, of course, be foolish to cancel the programme of development--the objective should be to get back as much as possible of the money which has been spent". We suggest that it might be wiser to write off the money spent as the cost of a useful lesson from bitter experience.

Many of the developments of technology in our time yield short term benefits while they degrade the total human environment, polluting water and air, and threatening the quality of life for future generations. In November 1968 a special study group of experts reported to the US Secretary of the Interior on "Noise and the Sonic Boom in Relation to Man". They pointed out that "every new technology carries its own adverse effects and these must receive attention equal to the technology itself. . . U Usually the public which reaps the benefits from a decision is different from the public which suffers the adversities. The decision-making should recognize both publics by providing for continuing work on both sides of the question, not at some distant timo in the future but right from the moment of decision."

We hope that in future Nature may consider new tcchnological proposals in this broader spirit, and not talk merely in terms of "getting back as much as possible of the money which has bcen spent". In the particular case of the Concorde, or of the American SST, a really critical appraisal of its commercial prospects alone might well have been enough to kill the project. In other possible technological developments, however, the immediate financial returns to the developers may well be very attractive, while the long term effects on the total human environment might be most deleterious. We trust that Nature, with its immense influence in the scientific world, will in future consider such projects in their broad implications for the human community in genoral.

\section{Yours faithfully,}

Willtam A. Shurclife JOHN T. EDSALL

Citizens League Against the Sonic Boom,

19, Appleton Street,

Cambridge,

Massachusetts, 02138.

1 The Anti-Concorde Project, 70 Lytton Ave., Letchworth, Herts, England.

2 Shurcliff, W. A. "SST and Sonic Boom Handbook" (Citizens League Against the Sonic Boom, 1968).

\section{New Constitution for British Physicists}

Srr,-The recent article in Nature $(220,952 ; 1968)$ on the Institute of Physics and the Physical Society has drawn attention to the fact that many of the members are discontent with the proposed changes in the structure of the institute and society which are associated with the application for a Royal Charter. Professor Blackman's letter in Nature $(221,105 ; 1969)$ has given details of the reasons for the disquiet felt by fellows of the Physical Society, and I would like to draw attention to a matter which is of no less concern to licentiates of the Institute of Physics.

The proposed membership changes which accompany the application for a Royal Charter will have the effect of depriving licentiates of their existing right to the use of an abbreviated designation of their grade. For licentiates, who have the right to use "L.Inst.P." are to become associates who will have no right to the use of an abbreviated designation. I consider that this is an unjustified reduction of status, and British physicists should clearly understand that the "intangible" advantages of a Royal Charter are being sought at the expense of a real deprivation to licentiates.

Yours faithfully,

G. WEST

25, Valley Crescent,

Wokingham,

Berkshire.

\section{Appointments}

Professor Dan Lewis, University College London, has been appointed a member of the University Grants Committee.

\section{Announcements}

The David Anderson-Berry Silver-Gilt Medal, together with an award of not less than $£ 100$, is to be presented by the Council of the Royal Society of Edin. burgh during 1969 in recognition of recent work on the effects of $\mathrm{X}$-rays and other forms of radiation on living tissues. Further information can be obtained from the General Secretary, Royal Society of Edinburgh, 22-24 George Street, Edinburgh 2, Scotland.

Corrigendum. In the book review by G. H. Williams entitled "Radical Ion Chemistry" (Nature, 221, 494; 1969) the first sentence of the third paragraph should read "The topics reviewed are : electron spin densities and their determination (James R. Bolton); metal ketyls and related radical ions including a discussion of the ion pair equilibria in which these species aro involved (Noboru Hirota); semidione radical ions (Glen A. Russell); the e.s.r. spectra of radical cations, with a short section on the preparation of these species (Gershon Vincow) ; . . ."

ERRATUM. In the article "Sex Determination Reconsidered" (Nature, 221, 410 ; 1969) "grandes hypotheses" should be "groundless hypotheses".

Erratum. In the article "Origins of Natural Gas and Petroleum" by W. G. Meinschein, Yaron M. Sternberg and Ronald. W. Klusman (Nature, 220, 1185; 1968), the following corrections are necessary: (1) page 1185, column 2, last line should read: ". . clements to form gas accumulations, and some gases, ... "; (2) page 1186 , column 2, line 7 should read: " . . lines, $y$, equals the concentrations of methane normalized to methane equal to 100 per cent and $y$ and ..." ; (3) page 1187, Fig. 3, curves $A(a)$ and $A(b)$ each should be shifted vertically until the upper end of each curve intersects the left $Y$-axis at 100 , thereby normalizing methane to 100 per cent. 